\title{
Germanium as a Sodium Ion Battery Material: In Situ TEM Reveals Fast Sodiation Kinetics with High Capacity
}

\author{
Xiaotang Lu, ${ }^{\dagger}$ Emily Adkins, ${ }^{\dagger}$ Yang He, ${ }_{\S}^{\ddagger}$ Li Zhong, ${ }^{\ddagger}$ Langli Luo, ${ }^{\S}$ Scott X. Mao, ${ }^{\ddagger}$ Chong-min \\ Wang, ${ }^{\S}$ Brian A. Korgel $^{+*}$
}

${ }^{\dagger}$ Department of Chemical Engineering, Texas Materials Institute, Center for Nano- and Molecular Science and Technology, The University of Texas at Austin, Austin, Texas 787121062, United States

${ }^{\S}$ Environmental Molecular Sciences Laboratory, Pacific Northwestern National Laboratory, Richland, WA 99354, United States

Department of Mechanical Engineering and Materials Science, University of Pittsburgh, Pittsburgh, Pennsylvania 15261, United States

* Corresponding author: korgel@che.utexas.edu; (T) 1-512-471-5633; (F) 1-512-471-7060

\section{Supporting Information}

Electrochemical testing. Ge nanowire anode slurries were composed of NWs/PAA/carbon at a weight ratio of 70/20/10. The typical mass of NWs was approximately 24 mg. $0.8 \mathrm{~mL}$ NMP was added as solvents before probe sonication for 30 minutes. The slurries were then transferred to a vacuum oven to evaporate excess solvent until the appropriate viscosity was obtained. After that, slurries were doctor-bladed onto copper foil and dried at $80{ }^{\circ} \mathrm{C}$ under vacuum overnight. In doctor blade process, the gap between blade and copper foil was fixed at $50 \mu \mathrm{m}$. The typical mass loading for each anode disk with $11 \mathrm{~mm}$ diameter hole-punched from coated copper foil was $0.03 \mathrm{mg}$.

In an argon-filled glovebox ( $0.05 \mathrm{ppm}$ oxygen), lithium ion coin cells were assembled using a nanowire electrode and $\mathrm{Li}$ foil as the counter electrode. Electrolyte was made as $1 \mathrm{M}$ $\mathrm{LiPF}_{6}$ dissolved in 1/1 w/w EC/DEC with 5 wt.\% FEC. Coin cell testing was done using an Arbin BT-2143 test uint cycling between 0.01-2 V vs. Li/ $/ i^{+}$. Capacities are calculated based on nanowire mass only. For clarity, rate $(\mathrm{C})$ and current density $(\mathrm{mA} / \mathrm{g})$ are both reported, and lithiation/delithiation capacity instead of charge/discharge capacity was used in this work.

After 1 cycle of Li activation, lithium ion coin cells were disassembled and the Ge nanowire electrodes were rinsed in DEC and dried for the following sodium ion coin cells assembly. In sodium ion coin cells, sodium foil was used as the counter electrode with $1 \mathrm{M}$ $\mathrm{NaClO}_{4}$ dissolved in $1 / 1 / 1 \mathrm{v} / \mathrm{v} / \mathrm{v} \mathrm{EC} / \mathrm{DEC} / \mathrm{FEC}$ as the electrolyte. The voltage window during cycling was between $0.01-2 \mathrm{~V}$ vs. $\mathrm{Na} / \mathrm{Na}^{+}$. Figure $\mathrm{S} 1$ shows the voltage profile of the Na-ion battery of the initial cycle. 


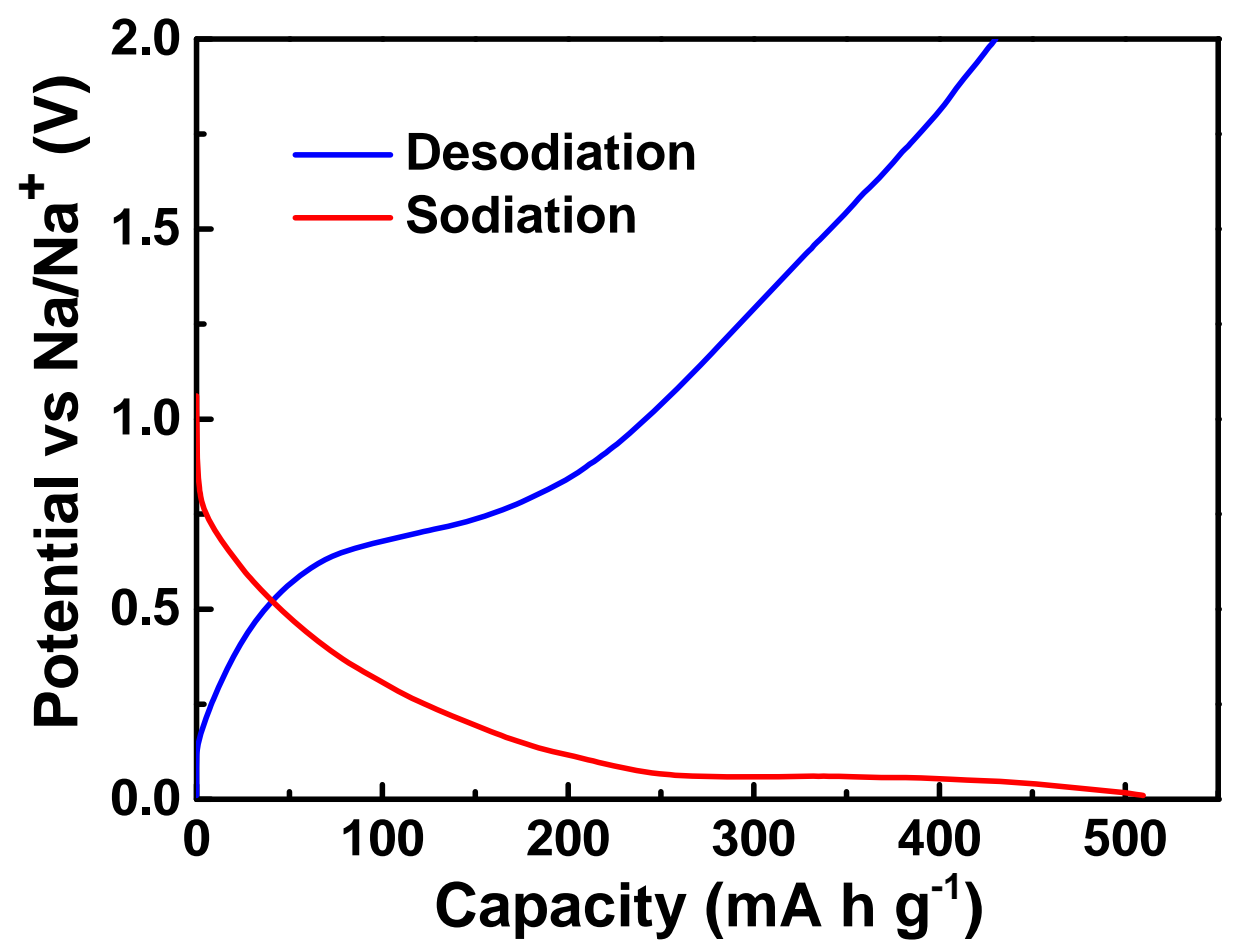

Figure S1. $1^{\text {st }}$ cycle voltage profile for Na-ion coin cell of Li-activated Ge nanowires at the cycle rate of $\mathrm{C} / 5$.

Additional data. Figure S2 shows compositional analysis of a Ge nanowire with Sn nanoparticles on its surface. Table S1 summarizes the diameter changes of five Ge nanowires before testing, after delithiation and after sodiation. Figure S3 shows the plot of volume expansion ratios vs $\mathrm{Na}$ content in $\mathrm{Na}_{\mathrm{x}} \mathrm{Ge}$. Figure $\mathrm{S} 4$ shows a TEM image of how Ge nanowires were bridged to prevent fast surface diffusion of $\mathrm{Na}$ along the nanowire surface. 

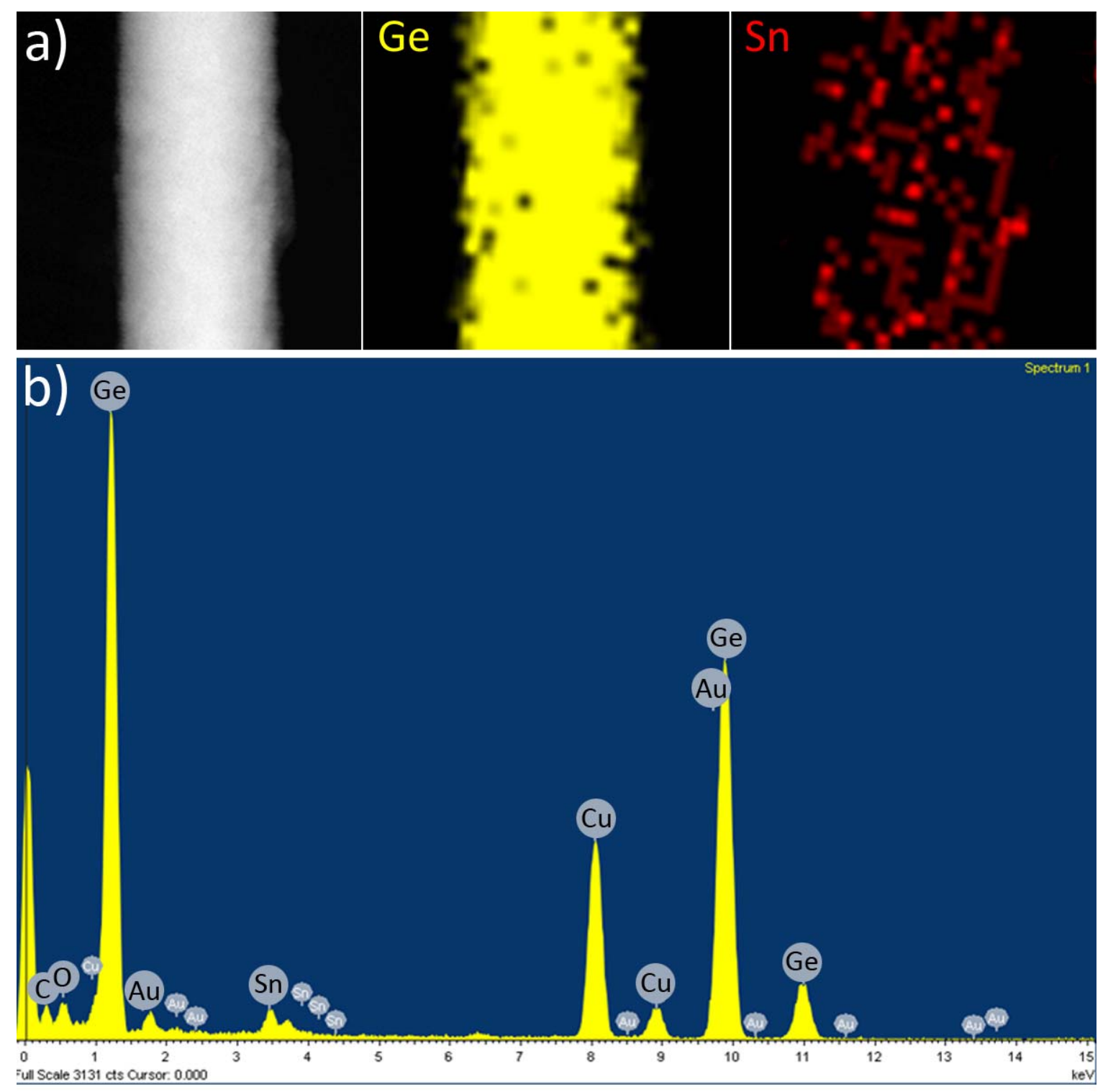

Figure S2. Elemental analysis of a Sn-coated Ge nanowire. (a) EDS mapping and (b) EDS spectrum of a Sn coated Ge nanowire. 
Table S1. Statistics of Observed Diameter Expansion for Ge Nanowires after Delithiation and Sodiation

\begin{tabular}{cccccc}
\hline Nanowire & $\begin{array}{c}\text { Original } \\
\text { Diameter } \\
D_{0}(\mathrm{~nm})\end{array}$ & $\begin{array}{c}\text { Diameter after } \\
\text { Delithiation } \\
D_{L}(\mathrm{~nm})\end{array}$ & $\begin{array}{c}\text { Diameter after } \\
\text { Sodiation } \\
D_{S}(\mathrm{~nm})\end{array}$ & $\mathrm{D}_{\mathrm{L}} / \mathrm{D}_{0}$ & $\mathrm{D}_{\mathrm{s}} / \mathrm{D}_{\mathrm{L}}$ \\
\hline$\# 1$ & 29 & 30.5 & 46 & $105.2 \%$ & $150.8 \%$ \\
$\# 2$ & 28.5 & 31 & 49 & $108.7 \%$ & $158.1 \%$ \\
$\# 3$ & 27 & 29 & 44 & $107.4 \%$ & $151.7 \%$ \\
$\# 4$ & 15 & 16 & 25.5 & $106.7 \%$ & $159.4 \%$ \\
$\# 5$ & 30 & 31.5 & 50 & $105 \%$ & $158.7 \%$ \\
$\# 6$ & 33 & 36 & 56 & $109.1 \%$ & $155.6 \%$ \\
\hline
\end{tabular}

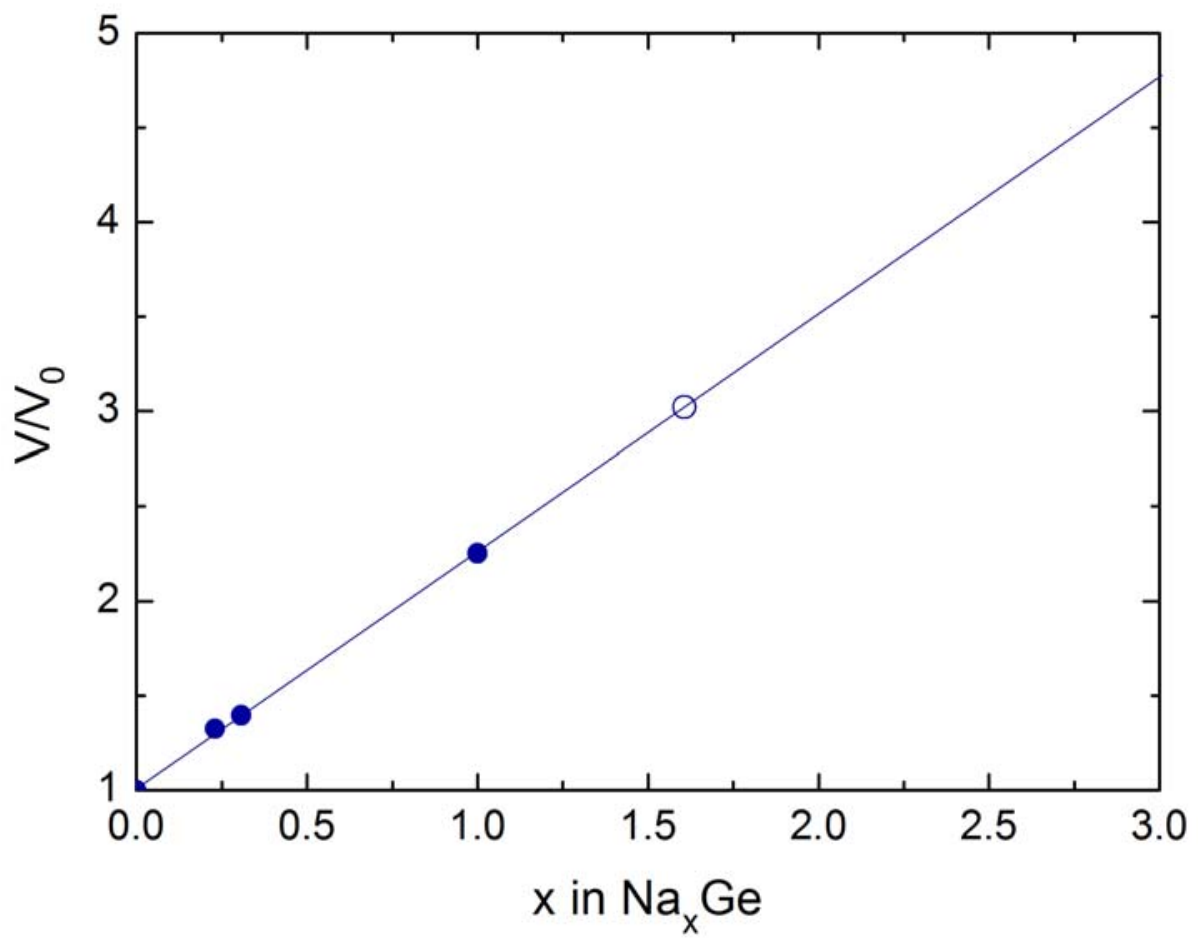

Figure S3. Plot of volume expansion ratios of $\mathrm{Na}_{\mathrm{x}} \mathrm{Ge}$ vs. $\mathrm{Na}$ contents. The volume expansion ratios of $\mathrm{Na}_{\mathrm{x}} \mathrm{Ge}\left(\mathrm{x} \leq 1\right.$, solid dots) are calculated from $\mathrm{Na}_{0.71} \mathrm{Ge}_{3.08}$ (PDF\#01-079-7533), ${ }^{1}$ $\mathrm{NaGe}_{3.25}$ (PDF\#01-079-7534) ${ }^{1}$ and $\mathrm{NaGe}$ (PDF\#01-089-2624). ${ }^{2}$ From the fitting line, the volume expansion ratio of $303 \%$ corresponds to $\mathrm{Na}_{1.6} \mathrm{Ge}$ (open circle). 


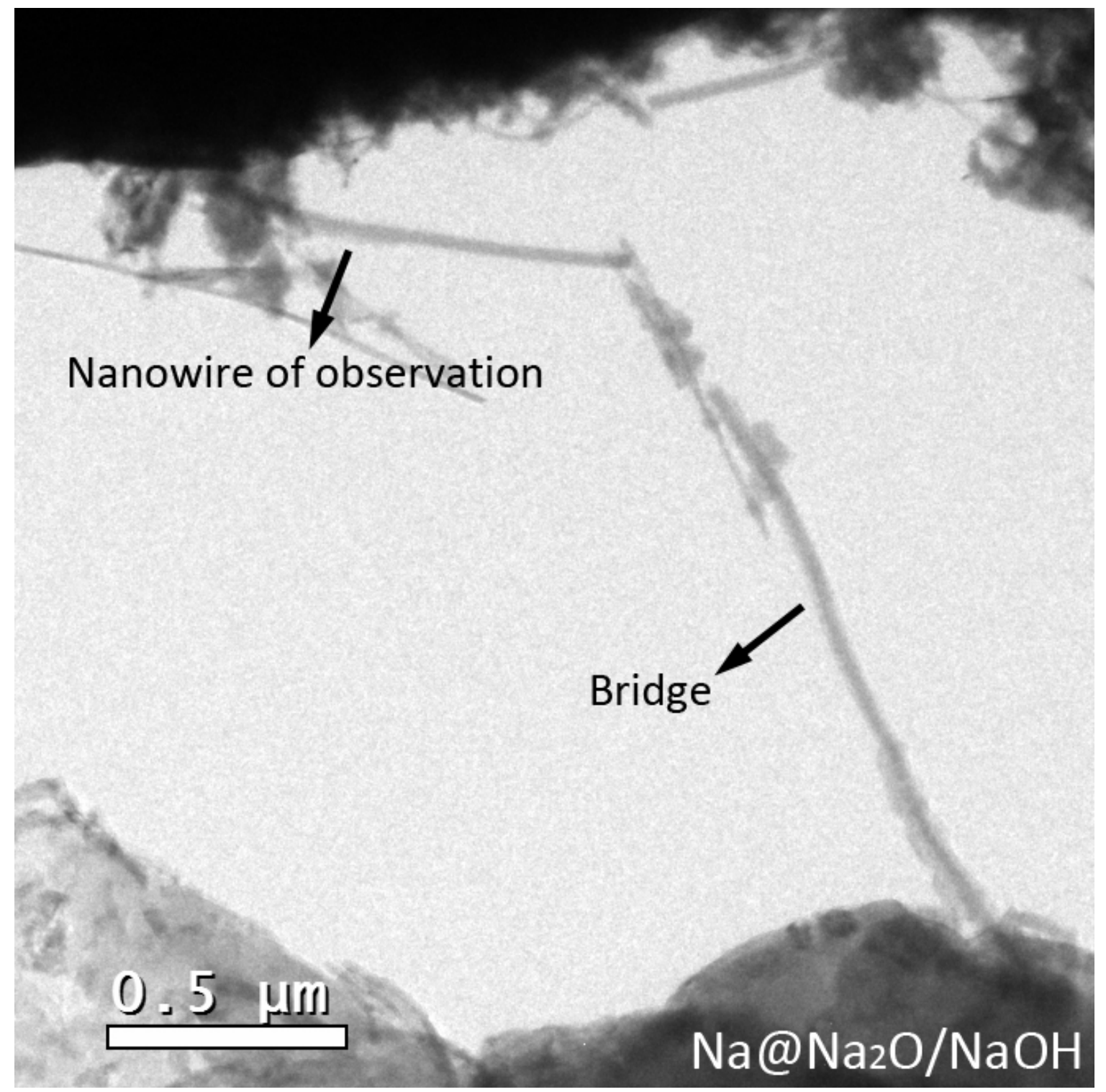

Figure S4. Bridging of nanowires to avoid fast surface diffusion of Na. Bridging the nanowires to avoid fast surface diffusion of $\mathrm{Na}$ from $\mathrm{Na} @ \mathrm{Na}_{2} \mathrm{O} / \mathrm{NaOH}$ reservoir.

\section{References}

(1) Beekman, M.; Stefanoski, S.; Wong-Ng, W.; Kaduk, J.A.; Huang, Q.; Reeg, C.; Bowers, C.R., Nolas; G.S. Structure and Thermal Conductivity of $\mathrm{Na}_{1-\mathrm{x}} \mathrm{Ge}_{3+\mathrm{z}}$. J. Solid State Chem. 2010, 183, 1272-1277.

(2) Witte, J.; Schnering, H. G.; Klemm, W. Das Verhalten Der Alkalimetalle Zu Halbmetallen. XI. Die Kristallstruktur von NaSi Und NaGe. Zeitschrift für Anorg. und Allg. Chemie 1964, 327, $260-273$. 